\title{
Receptor-receptor interactions of complement receptor type 3 in neutrophil membranes
}

\author{
Howard R. Petty* and Robert F. Todd III \\ -Department of Biological Sciences, Wayne State University, Detroit, Michigan, and ${ }^{\dagger}$ Department of Internal Medicine, \\ Simpson Memorial Research Institute, University of Michigan, School of Medicine, Ann Arbor
}

\begin{abstract}
The leukocyte integrin CR3 (CD11b/CD18) is known to participate in a variety of cell functions. Recent studies have indicated that CR3 may communicate with other plasma membrane receptors to carry out several cell functions. In this review we discuss these potential receptor-receptor interactions of CR3 and present a unifying model of CR3's diverse functions. J. Leukoc. Biol. 54: 492-494; 1993.
\end{abstract}

Key Words: Fc receptors - lectin-like interactions - target recognition - transmembrane signaling

\section{INTRODUCTION}

Cell membrane-associated proteins can be operationally classified as integral, peripheral, and glycophospholipid linked [1]. Membrane proteins are assembled from similar or dissimilar subunits in a variety of ways to form receptors, channels, and enzymes. For example, antigen receptors of $\mathrm{T}$ and B cells are composed of at least seven and five protein subunits, respectively [e.g., 2-5]. Whether multimeric membrane complexes are involved in neutrophil or macrophage transmembrane signaling is unknown. In this review we discuss the emerging theme of receptor-receptor interactions in neutrophil membranes with particular emphasis on CR3 (CD11b/CD18) as a membrane transducer, especially for glycophospholipid-linked proteins.

\section{CR3}

CR3 (CD11b/CD18), a leukocyte integrin, participates in a broad spectrum of adherence-related leukocyte functions including cell adherence, cytolysis, phagocytosis, and chemotaxis $[6,7]$. After SDS-PAGE, CR3 is found as a heterodimeric glycoprotein composed of 155- and 94-kd subunits [8]. Each subunit spans the membrane bilayer. CR3 interacts with the cytoskeleton and potentiates the release of cytoplasmic messengers [9-11]. CR3 is a pluripotent membrane recognition and triggering device. In addition to being the receptor for complement fragment iC3b [7], it recognizes zymosan [12], $\beta$-glucans [13], Escherichia coli, and lipopolysaccharide [14], Leishmania [15], and fibrinogen [16]. Carbohydrates expressed on CR3 are recognized by concanavalin A [17] and $E$. coli [18] lectins.

\section{CR3-TO-Fc $\gamma$ RECEPTOR INTERACTIONS}

Several lines of evidence support the hypothesis that CR3 interacts with $\mathrm{Fc} \gamma$ receptors. Early studies showed that Fab fragments of anti-CR3 monoclonal antibody inhibit im- munoglobulin G (IgG) dependent phagocytosis [8]. Furthermore, neutrophils from patients with leukocyte adhesion deficiency (LAD) express diminished IgG-dependent phagocytosis and cytolysis compared with controls $[19,20]$. Phagocytosis and rosetting experiments have indicated that CR3 may interact with $\mathrm{Fc} \gamma$ receptors $[21,22]$. Recent studies have indicated that CR3 and FcyRII (CDw32) cooperate in the generation of leukotriene $B_{4}[23]$. When neutrophils adhere to immune complex-coated surfaces, molecular proximity between CR3, but not Fcy receptors, and the cytoskeleton is triggered [11], providing physical evidence for the participation of CR3 in antibody-dependent functions. Further evidence for the interaction of these receptors comes from cocapping studies. We have shown that CR3 cocaps with Fc $\gamma$ RIIIB (CD16) and that specific saccharides, which interact with CR3's lectin-like site [12], inhibit cocapping [24]. The same saccharides decrease immune complex-dependent transmembrane signaling and superoxide production [25], suggesting that the receptor-receptor interactions identified in the cocapping experiments participate in signal transduction and superoxide production. Furthermore, studies using transfected fibroblasts have shown that neither CR3 or FcyRIIIB is capable of independently triggering antibodydependent phagocytosis, whereas cells coexpressing these receptors display antibody-dependent phagocytosis (Krauss, J.C., Poo, H., Xue, W., Mayo-Bond, L., Todd, R.F., Petty, H.R., manuscript submitted).

\section{CR3 AS A MEMBRANE TRANSDUCER}

The presence of membrane transducers for GPI-linked proteins has been variously postulated in the scientific literature [26]. We propose that CR3 is one such transducer. Figure 1 shows a schematic summary of the potential extramembrane and intramembrane interactions of CR3. The extramembrane interactions, as described above, can be classified as protein dependent and carbohydrate dependent. CR3's carbohydrate-dependent recognition mechanisms include both interactions mediated by its lectin-like site and interactions of its saccharide chains with other lectins. In addition to its interactions with macromolecules outside the plane of the membrane, CR3 can communicate with other plasma membrane proteins. In the preceding paragraph we described various experiments that provide evidence for interactions between CR3 and Fc $\gamma$ RIIIB and CR3 and Fc $\gamma$ RII.

\footnotetext{
Abbreviations: fMLP, $N$-formylmethionyl-leucyl-phenylalanine; IgG, immunoglobulin G; LAD, leukocyte adhesion deficiency; $\mathrm{uPaR}$, urokinasetype plasminogen activator receptor.

Reprint requests: Howard R. Petty, Department of Biological Sciences, Wayne State University, Detroit, MI 48202.

Received May 2, 1993; accepted June 21, 1993.
} 


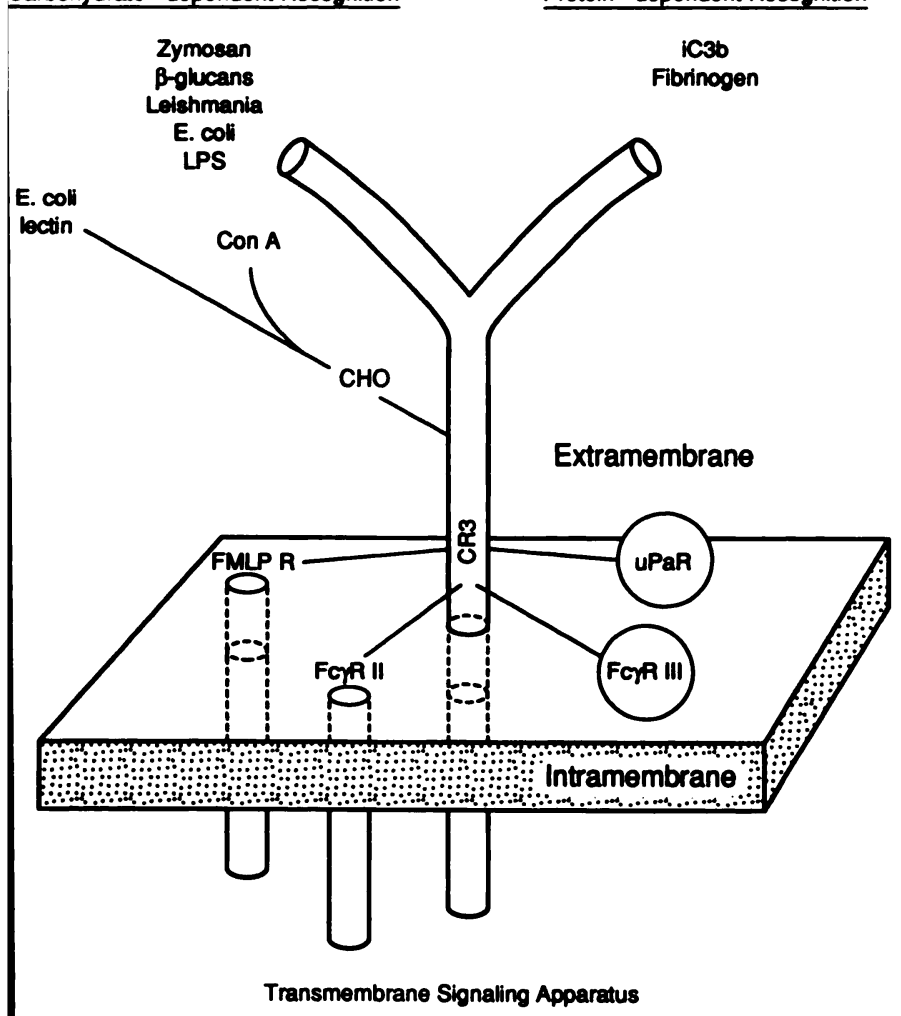

Fig. 1. A highly schematic illustration of potential extramembrane and intramembrane interactions of CR3. Extramembrane interactions are shown above and below the membrane. Interactions with external macromolecules are listed as carbohydrate or protein dependent. Potential intramembrane interactions with FcyRIIIB, FcyRII, $u P a R$, and fMLP receptors are shown.

These interactions may help to explain the co-up-regulation and co-down-regulation of these receptors $[27,28]$ and the nterplay between the receptors (e.g., Fc $\gamma$ RII-Fc $\gamma$ RIIIB [29]) in cell membranes.

In addition to Fc $\gamma$ Rs, CR3 apparently interacts with other receptors. We have shown that the urokinase-type plasminogen activator receptor ( $\mathrm{UPaR})$, another heavily glycosylated GPI-linked protein, cocaps with CR3 [30]. Furthermore, Kew et al. [31] have provided evidence that FcrRIIIB communicates with the fMLP receptor. To integrate this work with our own, we have studied the surface distribution of MLP receptors using a fluorescent analogue. These unpubished experiments have shown that ligated fMLP receptors cocap with CR3 and collect at sites of antibody-dependent binding and phagocytosis. This may eventually provide a better molecular rationale for the defective chemotaxis seen using LAD neutrophils.

\section{CR3 COMMUNICATES WITH THE CYTOSKELETON}

Neutrophil functions such as chemotaxis, phagocytosis, and adherence require the participation of cytoskeletal strucures. Integrin molecules are known to be associated with the fytoskeleton [1]. A recent study has shown that integrins ransmit mechanical signals to the cytoskeleton [32]. When CR3 binds iC3b, one of its potential ligands, its proximity o the cytoskeletal actin filaments is dramatically enhanced 33]. As mentioned earlier, immune complexes enhance CR3, but not Fc $\gamma R$, proximity to microfilaments [11]. This uggests that several receptors could affect transmembrane hemical signal transduction and mechanotransduction via CR3.
The cytoskeleton may also play a role in receptor-receptor interactions for transmembrane proteins. CR3 clustering [34] may be a reflection of their cytoskeletal attachments [33], although the detailed nature of CR3-CR3 interactions is unknown. It is also possible that other specific transmembrane proteins, such as the fMLP receptor, might be tethered to the cytoskeleton in a fashion that promotes interactions with CR3.

\section{PROSPECTS}

We are all familiar with the idea that extracellular ligands bind to membrane receptors, but perhaps less so with interactions between ostensibly separate receptors within a membrane. These interactions need not be static. Receptors probably display various affinities for one another that could be modulated by cytoplasmic messengers or ligation status. These interactions may be restricted to the reduced dimensionality of membranes, in analogy with the spontaneous formation of insulin heterotetrameric receptors in membranes but not in solution [1]. The effector recognition complex formed by CR3 and its several partners could generate a diversity of signals; for example, if each of the three transmembrane proteins mentioned above could generate one cytoplasmic signal, seven different cytoplasmic combinations can be obtained. In addition, CR3 could provide other membrane receptors, such as FcrRIIIB and uPaR, with a membrane mechanotransduction device to affect phagocytosis and locomotion, respectively. Receptor-receptor interactions of integrins have also been observed for $\mathrm{T}$ cells [35]. Further experiments will better define the nature of these membrane complexes and their role in the promotion of effector functions.

\section{ACKNOWLEDGMENTS}

This work was supported by NIH grants AI/CA27409 (to H.R.P.) and CA39064 (to R.F.T.).

\section{REFERENCES}

1. Petty, H.R. (1993) Molecular Biology of Membranes: Structure and Function. Plenum Press, New York.

2. Ashwell, J.D., Klausner, R.D. (1990) Genetic and mutational analysis of the T-cell antigen receptor. Annu. Rev. Immunol. 8, 139-167.

3. Clevers, H., Alarcon, B., Willeman, T., Terhorst, C. (1988) The $T$ cell receptor/CD3 complex: a dynamic protein ensemble. Annu. Rev. Immunol. 6, 629-662.

4. Venkitaraman, A.R., Williams, G.T., Dariavach, P., Neuberger, M.S. (1991) The B cell antigen receptor of the five immunoglobulin classes. Nature 352, 777-781.

5. Chang, C.-C., Alhasan, S., Rosenspire, A.J. (1992) G protein mediated signal transduction: membrane immunoglobulin associated phosphoproteins identified in octyl- $\beta$-glucoside lysates of normal B cells. Immunol. Lett. 32, 193-200.

6. Springer, T.A., Anderson, D.C. (1986) The importance of the Mac-1, LFA-1 glycoprotein family in monocyte and granulocyte adherence, chemotaxis, and migration into inflammatory sites: insights from an experiment of nature. In Biochemistry of Macrophages. Ciba Foundation Symposium 118 (D. Evered, J. Nugent, and M. O'Connor, eds) Pitman, London, 102-126.

7. Arnaout, M.A. (1990) Structure and function of the leukocyte adhesion molecules CD11/CD18. Blood 75, 1037-1050.

8. Arnaout, M.A., Todd, R.F., Dana, N., Melamed, J., Schlossman, S.F., Colten, H.R. (1983) Inhibition of phagocytosis of 
complement C3 or immunoglobulin G coated particles and of C3bi binding by monoclonal antibodies to the monocytegranulocyte membrane glycoprotein (Mol). J. Clin. Invest. 72, 171-179.

9. Fallman, M., Lew, D.P., Stendahl, O., Andersson, T. (1989) Receptor-mediated phagocytosis in human neutrophils is associated with increased formation of inositol phosphates and diacylglycerol: elevation in cytosolic free calcium and formation of inositol phosphates can be dissociated from accumulation of diacylglycerol. J. Clin. Invest. 84, 886-891.

10. Salmon, J.E., Grogle, N.L., Edberg, J.C., Kimberly, R.P. (1991) Fcy receptor III induces actin polymerization in human neutrophils and primes phagocytosis mediated by Fcy receptor II. J. Immunol. 146, 997-1004.

11. Zhou, M.-J., Poo, H., Todd, R.F., Petty, H.R. (1992) Surface bound immune complexes trigger transmembrane proximity between complement receptor type 3 and the neutrophil's cortical microfilaments. J. Immunol. 148, 3550-3553.

12. Ross, G.D., Cain, J.A., Lachmann, P.J. (1985) Membrane complement receptor type three (CR3) has lectin-like properties analogous to bovine conglutinin and functions as a receptor for zymosan and rabbit erythrocytes as well as a receptor for iC3b. J. Immunol. 134, 3307-3315.

13. Ross, G.D., Cain, J.A., Myones, B.L., Newman, S.L., Lachmann, P.J. (1987) Specificity of membrane complement receptor type three (CR3) for $\beta$-glucans. Complement 4, 61-74.

14. Wright, S.D., Jong, M.T.C. (1986) Adhesion-promoting receptors on human macrophages recognize Escherichia coli by binding to lipopolysaccharide. J. Exp. Med. 164, 1876-1888.

15. Wilson, M.E., Pearson, R.D. (1988) Roles of CR3 and mannose receptors in the attachment and ingestion of Leishmania donovani by human mononuclear phagocytes. Infect. Immun. 56, 363-369.

16. Wright, S.D., Weitz, J.I., Huang, A.I., Levin, S.M., Silverstein, S.C. (1988) Complement receptor type 3 (CD11b/CD18) of human polymorphonuclear leukocytes recognizes fibrinogen. Proc. Natl. Acad. Sci. USA 85, 7734-7738.

17. Schmalstieg, F.C., Rudloff, H.E., Anderson, D.C. (1986) Binding of adhesive protein complex (LFA-1/Mac-1/p150,95) to concanavalin A. J. Leukoc. Biol. 39, 193-203.

18. Gbarah, A., Gahmberg, C.G., Ofek, I., Jacobi, U., Sharon, N. (1991) Identification of the leukocyte adhesion molecules CD11 and CD18 as receptors for type 1-fimbriated (mannose-specific) Escherichia coli. Infect. Immun. 59, 4524-4524.

19. Anderson, D.C., Schmalstieg, F.C., Arnaout, M.A., Kohl, S., Tosi, M.F., Dana, N., Buffone, G.J., Hughes, B.J., Brinkley, B.R., Dickey, W.D., Abramson, J.S., Springer, T.A., Boxer, L.A., Hollers, J.M., Smith, C.W. (1984) Abnormalities of polymorphonuclear leukocyte function associated with a heritable deficiency of high molecular weight surface glycoproteins (GP138): common relationship to diminished cell adherence. J. Clin. Invest. 74, 536-551.

20. Kohl, S., Loo, L.S., Schmalstieg, F.S., Anderson, D.C. (1986) The genetic deficiency of leukocyte surface glycoprotein Mac-1, LFA-1, p150,95 in humans is associated with defective antibodydependent cellular cytotoxicity in vitro and defective protection against herpes simplex virus infection in vivo. J. Immunol. 137, 1688-1694.

21. Brown, E.J., Bohnsack, J.F., Gresham, H.D. (1988) Mechanism of inhibition of immunoglobulin G-mediated phagocytosis by monoclonal antibodies that recognize the Mac-1 antigen. J. Clin. Invest. 81, 365-375.

22. Graham, I.L., Gresham, H.D., Brown, E.J. (1989) An immobile subset of plasma membrane CD11b/CD18 (Mac-1) is involved in phagocytosis of targets recognized by multiple receptors. J. Immunol. 142, 2352-2358.

23. Graham, I.L., Lefkowith, J.B., Anderson, D.C., Brown, E.J. (1993) Immune complex-stimulated neutrophil LTB $_{4}$ production is dependent on $\beta_{2}$ integrins. J. Cell Biol. 120, 1509-1517.

24. Zhou, M.-J., Todd, R.F., van de Winkel, J.G.J., Petty, H.R. (1993) Cocapping of the leukoadhesion molecules complement receptor type 3 and lymphocyte function-associated antigen-1 with Fcy receptor III on human neutrophils: possible role of lectin-like interactions. J. Immunol. 150, 3030-3041.

25. Sehgal, G., Zhang, K., Todd, R.F., Boxer, L.A., Petty, H.R. (1993) Lectin-like inhibition of immune complex receptor-mediated stimulation of neutrophils: effects on cytosolic calcium release and superoxide production. $J$. Immunol. 150, 4571-4580.

26. Robinson, P.J. (1991) Phosphatidylinositol membrane anchors and $T$-cell activation. Immunol. Today 12, 35-41.

27. Wolf, H.M., Mannhalter, J.W., Salzmann, H.C., Gottilicher, J., Ahmad, R., Eibl, M.M. (1988) Phagocytosis of serumopsonized zymosan down-regulates the expression of CR3 and FCRI in the membrane of human monocytes. J. Immunol. 141, 3537-3543.

28. van Epps, D.E., Bender, J.G., Simpson, S.J., Chenoweth, D.E. (1990) Relationship of chemotactic receptors for formyl peptide and C5a to CR1, CR3, and Fc receptors on human neutrophils. J. Leukoc. Biol. 47, 519-527.

29. Naziruddin, B., Duffy, B.F., Tucker, J., Mohanakumar, T. (1992) Evidence for cross-regulation of Fc $\gamma$ RIIIB (CD16) receptor-mediated signaling by FcyRII (CD32) expressed on polymorphonuclear neutrophils. J. Immunol. 149, 3702-3709.

30. Xue, W., Kindzelsky, A., Todd, R.F., Petty, H.R. (1993) Cocapping of CR3 with the urokinase receptor. J. Immunol. 150, 308A (abstract).

31. Kew, R.R., Grimaldi, C.M., Furie, M.B., Fleit, H.B. (1992) Human neutrophil FcyRIIIB and formyl peptide receptors are functionally linked during formyl-methionyl-leucylphenylalanine-induced chemotaxis. J. Immunol. 149, 989-997.

32. Wang, N., Butler, J.P., Ingber, D.E. (1993) Mechanotransduction across the cell surface and through the cytoskeleton. Science 260, 1124-1127.

33. Zhou, M.-J., Todd, R.F., Petty, H.R. (1991) Detection of transmembrane linkages between immunoglobulin or complement receptors and the neutrophil's cortical microfilaments by resonance energy transfer microscopy. J. Mol. Biol. 218, 263-268.

34. Petty, H.R., Francis, J.W., Todd, R.F., Petrequin, P., Boxer, L.A. (1987) Neutrophil C3bi receptors: formation of membrane clusters during cell triggering requires intracellular granules. J. Cell. Physiol. 133, 235-242.

35. Rosenman, S.J., Ganji, A.A., Tedder, T.F., Gallatin, W.M. (1993) Syn-capping of human T lymphocyte adhesion/activation molecules and their redistribution during interaction with endothelial cells. J. Leukoc. Biol. 53, 1-10. 